\title{
STABILITY ANALYSIS OF OPEN PIT SLOPE BY FINITE DIFFERENCE METHOD
}

\author{
K. Soren ${ }^{1}$, G. Budi ${ }^{2}$, P. Sen ${ }^{3}$ \\ ${ }^{1}$ Research Scholar, Mining Engineering, Indian School of Mines, Jharkhand, India \\ ${ }^{2}$ Assistant Professor, Mining Engineering, Indian School of Mines, Jharkhand, India \\ ${ }^{3}$ Professor, Mining Engineering, Indian School of Mines, Jharkhand, India
}

\begin{abstract}
Open pit slope stability analysis has been performed to assess the slope deformation, state of stresses at critically instable failure zones, different failure modes and safe \& functional design of excavated slopes using the numerical modeling technique, finite difference method. The purpose of slope stability analyses by numerical modeling in rock mechanics is not only to provide specific values of stress and strain at specific points but is also to enhance our understanding of the processes involved to finding instable zones, investigation of potential failure mechanisms, designing of optimal slopes with regard to safety, reliability, economics, and designing possible remedial measures. As part of the rock mass, the discontinuities inherently affect the strength and the deformational behavior of slopes in rock mass containing sets of ubiquitous joints. In this paper the finite difference method, FLAC (Fast Lagrangian Analysis of Continua) of numerical modeling technique is used to predict the stress-strain behavior of pit slope and to evaluate the stability analysis of open pit slope. Ubiquitous joint model, which is an anisotropic plasticity model that includes weak planes of specific orientation embedded in Mohr-Coulomb solids, has been adopted to account for the presence of weak planes, such as weathering joints, bedding planes, faults, joints in FLAC Mohr-Coulomb model. Thus by studying the distribution of stress, displacement and factor of safety, the stability analysis of pit slope has been evaluated and suggestions based on the numerical analysis has been presented.
\end{abstract}

Keywords: open pit slope stability; Numerical model; Ubiquitous joint model; Jointed rock mass; Finite Difference Method.

\section{INTRODUCTION}

The primary objectives of the open pit slope stability analyses are performed to investigate the pit slope stability conditions, potential failure mechanism, slope sensitivity or susceptibility and to design optimum pit slope angles in terms of safety, reliability and economically profitable. In the process of stability analysis of open pit slopes in jointed rock mass, a number of steps and levels of analyses are required, from local bench design to overall stability of the high wall open pit rock slopes. This process requires the use of a variety of methods of analyses and software ranging from limit equilibrium methods to more involved numerical analyses methods such as distinct elements, finite elements and finite difference methods which can capture detailed geology input parameters and different types of failure modes. Stability of open pit slope depends on geometry of slope, rock mass characteristics and shear strength behaviour of the joints [1]. Since a rock mass is not a continuum, its behaviour is dominated by discontinuities such as joints, bedding planes and faults. In general, the presence or absence of discontinuities has a profound influence on the stability of rock slopes.
The discontinuities such as various geological structures joints, weak bedding planes, faults, weak schistocity planes and weak zones has been long recognized in rock mechanics which significantly influence the response of rock masses to loadings and surface excavations [2]. Generally, at smaller scales discontinuities exert greater influence on behaviour than do intact rock properties. In small slopes, failure mechanisms such as planar and wedges, which are controlled by joints, are common. Of the various numerical methods used for the stress analysis today, the family of Discrete Element Methods (DEMs) and Discontinuous Deformation Analysis (DDA) have been considered to be the well-suited to the problems of blocky and joint network rock masses. Recently however, it has been demonstrated that the Finite Element Method (FEM) with explicit representation of discontinuities with joint elements is a credible alternative $[3,4,5]$.

The objective of this paper is to present the numerical analysis method of FDM, FLAC software which has been used for the optimization of the open pit slope design and the analysis of different modes of slope failures occurred in an open pit mines have also been discussed using the FLAC slope models of the various slope failure mechanism. This paper also deals with the evaluation of factor of safety of slope by FLAC software, 
FLAC/Slope using shear strength reduction method in order to understand the instability failure mechanism of open pit slope and stress deformation response of slope in a typical open pit mine. Through the analysis of various modes of slope failure examples in open pit mine, it shows how these mechanisms depend on slope geometry and change with increasing slope angles.

\section{NUMERICAL MODELLING}

Numerical modelling technique is an efficient method that is widely used in various fields of science and rock engineering. Numerical modeling for rock mechanics has been developed for the design of rock engineering structures in or on it at different circumstances and for different purposes. Numerical modelling techniques provide an approximate solution to problems which otherwise cannot be solved by conventional methods, e.g. complex geometry, material anisotropy, nonlinear behaviour, in situ stresses etc. Numerical analysis allows for material deformation and failure; modelling of pore pressures, creep deformation, dynamic loading, assessing effects of parametric variations etc. Numerical modelling is used to investigate a variety of problems in rock slope behaviour, underground mining and tunnelling engineering which can assist the geo-technical engineer in designing underground excavations, surface excavations and support systems. If extensive geological and geo-technical data are available, then comprehensive predictions of deformations, stability and support loads can be made by numerical stress analyses and the model can be used to perform parametric studies, providing insight into the possible range of responses of a system, given the likely ranges for the various parameters. This understanding of the key parameters can then help set priorities for site investigation and material testing, which in turn will produce data that are used in design of slopes.

Due to the widespread availability of powerful computers, the FDM with explicit modelling of the behaviour of individual joints can be used for practical engineering in jointed rock masses. This has also been facilitated by the development of techniques for generating networks of discrete fractures, and the development of the Shear Strength Reduction (SSR) method. SSR analysis [6, 7, 8] allows factors of safety of slopes to be calculated with numerical methods. Although FDM-based SSR analysis is an alternative to conventional limit equilibrium methods (LEM) in many cases, its ability to readily combine slip along joints with failure through intact material offers several advantages in the modelling of jointed rock mass problems. Perhaps, the greatest benefit of FDMbased SSR analysis is that it can automatically determine the broad variety of failure mechanisms with no prior assumptions regarding the type, shape or location.

Strength reduction FLAC method has been used to analyze slope stability which can be judged by reducing residual shear strength, changing yield strength criterion of rocks, calculating the stress and strain of slope rocks, checking the displacement development of landslide [9, 10]. Application of limit equilibrium method to solve $3 \mathrm{D}$ problems is rather limited due to several simplifying assumptions $[11,12,13]$. It must be noted, however, that an increasing number of investigators use $3 \mathrm{D}$ numerical calculations for estimating slope stability [14, 15]. The factor of safety (FoS) for slope may be computed by reducing shear strength of rock or soil in stages until the slope fails. This method is called shear strength reduction technique (SSR). FLAC code is often applied for estimating factor of safety for rock slopes $\left[16,17_{\mathrm{a}, \mathrm{b}}\right]$ or even foliated rock slopes [18]. It is also applied in evaluating stability of soft rock slope perforated by underground openings [19]. FLAC is also widely used for analyzing stability of soil slopes [14, 15]. Sometimes FLAC is even used for slope stability engineering in combination with other methods. SSR technique is often used with FEM to solve quite sophisticated problems such as estimating stability of slope reinforces by piles [20, 21] or slope with horizontal drains [22]. A good overview of FEM application for slope stability engineering may be found in [23]. Advantages and disadvantages of SSR and LEM are presented in [24, 25]. The majority of investigators prefer using FEM or FDM for estimation of factor of safety for slopes.

With regard to the analysis of slopes in a homogeneous rock mass, the use of rock mass classification methods has become common for the determination of rock mass strength and deformation parameters. The rock mass classification numbers Q [26] and RMR [27] and, more recently, the Geological Strength Index GSI [28] have been correlated with the rock mass modulus, rock mass strength parameters both (HoekBrown and Mohr-Coulomb) and the unconfined compressive strength of the rock mass. Correlations of significance are with the rock mass deformation modulus [29] and with the rock mass strength parameters. On the basis of [30] and [31] the rock mass input parameters on rock mass classification data, and made use of a finite difference method to evaluate the stability of rock slopes in open pit mines. Numerical modeling is finding increasing application, particularly for defining potential failure modes. However, some degree of calibration is required before the numerical models can be considered predictive in the design sense. Prediction of behaviour, which is very significantly involved in the analysis and design of open pit mine slopes, requires a very thorough understanding of the mechanisms of deformation and behaviour of the slopes.

\section{OPEN PIT SLOPE FAILURE MECHANISMS}

A realistic design of open pit rock slopes requires (1) a good understanding of the dominant failure mechanisms in open pit rock slopes, and (2) a design tool that can be used to assess the stability of a slope subjected to various failure mechanisms. Methods for jointed rock slope stability analysis span a very wide range in the simplest form; they can be purely empirical guideline. More complex analysis methods can explicitly 
account for slope geometry, geological structure, rock stress conditions, geo-hydrological conditions and rock mass characteristics. In this group, one finds both limit equilibrium methods and numerical modeling. The basis for design must be an understanding of the failure mechanisms in jointed rock slopes. Unfortunately, failure mechanisms of high rock slopes, especially in hard jointed rock, are generally poorly understood and/or known [32].

\subsection{Pit Slope Stability Analysis}

In this section, typical pit slope stability analyses for a variety of failure modes have been discussed. The objective of this section is to show how numerical models can be used to simulate the pit slope behavior and compute safety factors for typical field problems. Modeling issues important in each of the following failure modes of jointed rock masses such as plane failure, toppling failure (block and flexural) and circular failure. Plane failure modes that involve rigid blocks sliding on planar joints that daylight in the slope face and toppling failure modes involve rotation and thus usually are difficult to solve using limit equilibrium methods. Block toppling involves free rotation of individual blocks, whereas flexural toppling involves bending of rock columns or plates. Block toppling occurs where narrow slabs are formed by joints dipping steeply into the face, combined with flatter crossjoints. The cross-joints provide release surfaces for rotation of the blocks. In the most common form of block toppling, the blocks, driven by self-weight, rotate forward out of the slope. Flexural toppling occurs when there is one dominant, closely spaced, set of joints dipping steeply into the face, with insufficient cross-jointing to permit free rotation of blocks (Figure 6). The columns bend out of the slope like cantilever beams as shown in (Figure 4) in the case of toppling failure. Following are the different modes of slope failure in open pit mines.

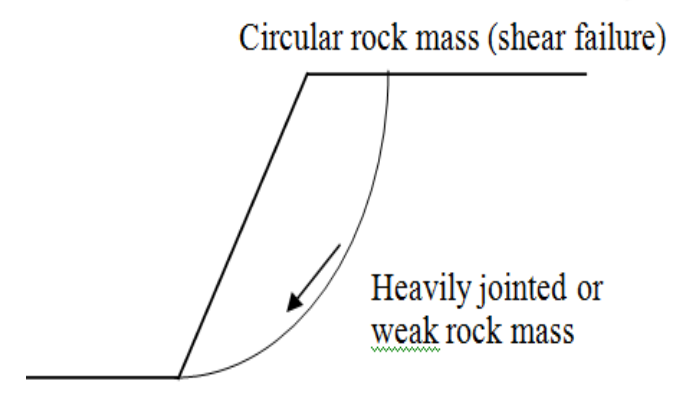

Fig.1 Schematic diagram depicting Circular failure in weak/weathered rock of an open pit mines.

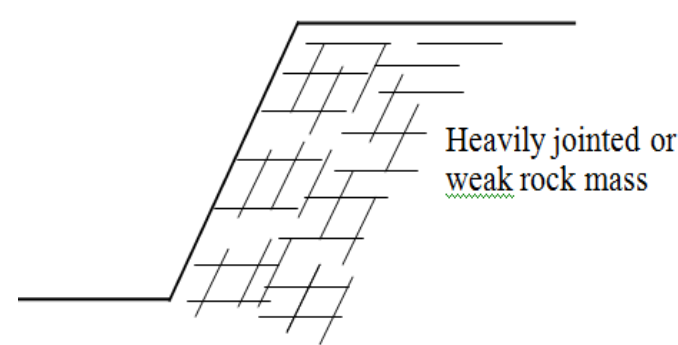

Fig. 2 Schematic diagram depicting circular failure in heavily jointed rock mass

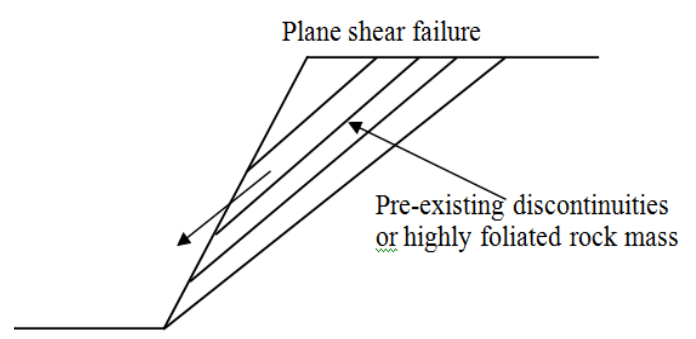

Fig. 3 Schematic diagram depicting the Plane failure mechanism in open pit

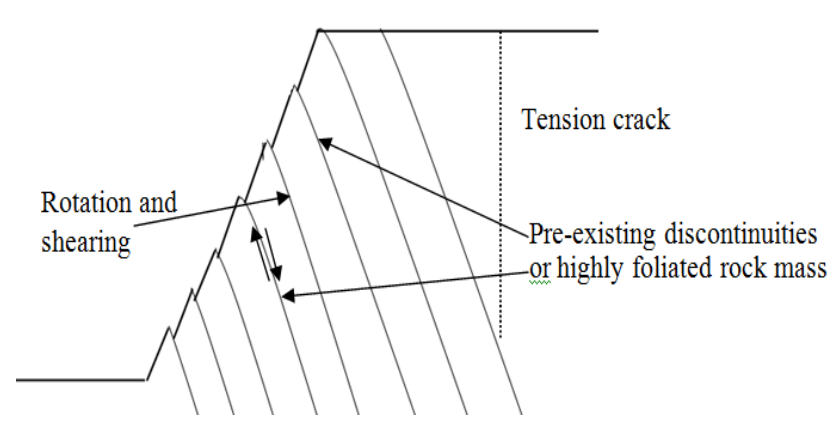

Fig. 4 Schematic diagram depicting the Toppling failure mechanism in open pit

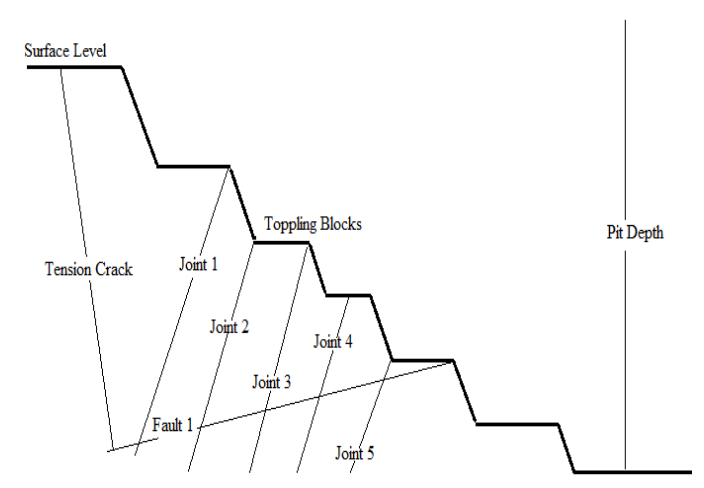

Fig. 5 Schematic diagram depicting the Toppling failure (Block type) mechanism in open pit. 


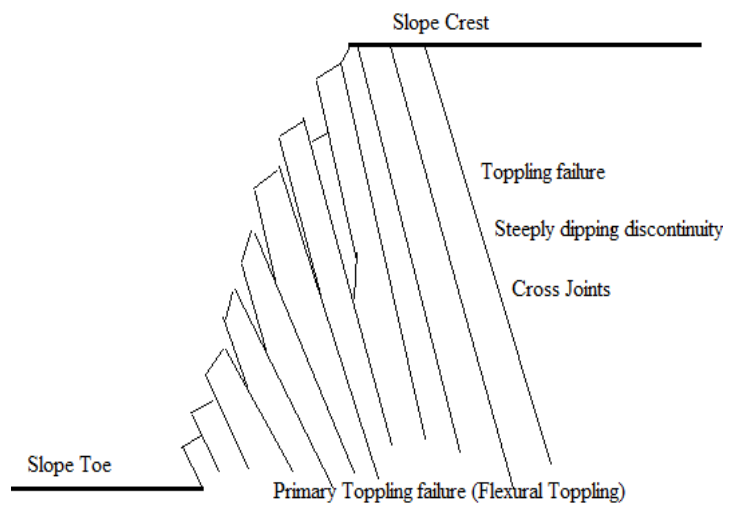

Fig. 6 Schematic diagram depicting the Toppling failure (Flexural type) mechanism in open pit mines.

The three main components which are to be considered for an open pit slope design in the view of pit slope stability conditions are as follows (Figure 7). First, the overall pit slope angle from crest to toe that incorporates all ramps and benches. Second, the inter-ramp angle is the slope (i.e the angle of crest of the ram to the toe of the slope), or slopes, lying between each ramp that will depend on the number of ramps and their widths. Third, the face angle of individual benches depends on vertical spacing between benches, or combined multiple benches, and the width of the benches required to contain minor rock falls [33].The factors that may influence stability of slope designing conditions are the slope height, geology, rock strength, ground water pressures and damage to the face by blasting etc.

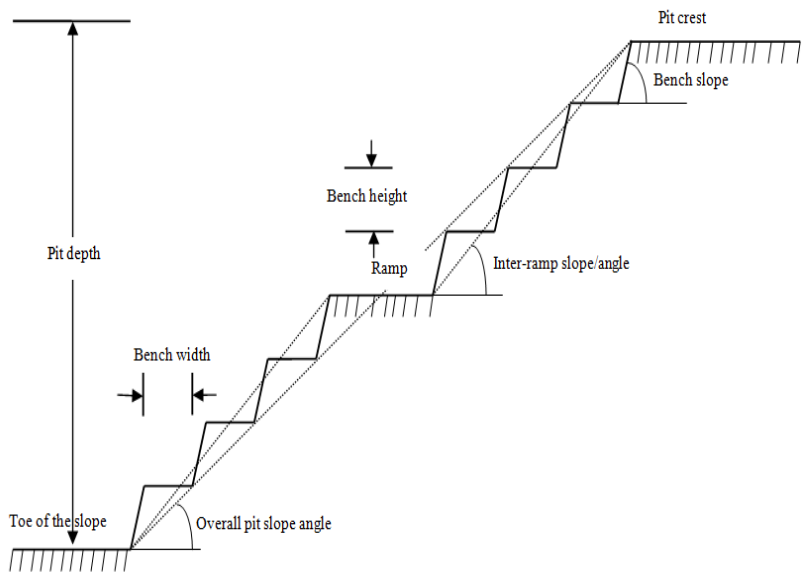

Fig.7 Typical open pit slope geometry showing relationship between overall slope angle, inter-ramp angle and bench geometry.

\section{NUMERICAL ANALYSIS}

\subsection{Finite Difference Method FLAC/Slope}

FLAC/Slope is a numerical modelling code which is based on finite difference method for advanced geotechnical analyses of soil, rock, and structural support in two and three dimensions. It is used in analyzing, testing, and designing of pit slopes by geotechnical, civil, and mining engineers. It is designed to accommodate any kind of geotechnical engineering projects where continuum analysis is necessary [34]. FLAC/Slope utilizes an explicit finite difference formulation that model complex behaviors are not readily suited to FEM codes, such as problems that consist of several stages, large displacements and strains, non-linear material behavior and unstable systems. FLAC/Slope is an abbreviation of calculated software "Fast Lagrangian Analysis of Continua". The open pit slope has been simulated using FLAC/Slope (version 5.0) developed by Itasca consulting group [35].

\subsection{Arithmetic Introduction for FLAC/Slope}

FLAC applies explicit finite difference method substituting for concealed finite difference method which was originally extensively used. Programming divides the medium of computing domain as several 2-dimension units which are connected by nodes with each other [36, 37]. The difference between the gridding divisions and the finite method is that the grids are divided as physical grid and mathematical grid, and the two kinds are mutual projection.

\subsection{Generation of Finite Difference Mesh}

FLAC has been used for analyzing the movements of rock mass and deformable analysis of slope failure in a typical open pit mines. For analysis of slope stability in open pit mine, the slope model is first divided into rock blocks that are then internally discretized into finite difference square elements (Figure 8). In fact, the entire model geometry, including excavations, is created using discontinuities, which makes it fairly easy to create complex geometries in FLAC. Consequently, FLAC may overestimate the collapse load.

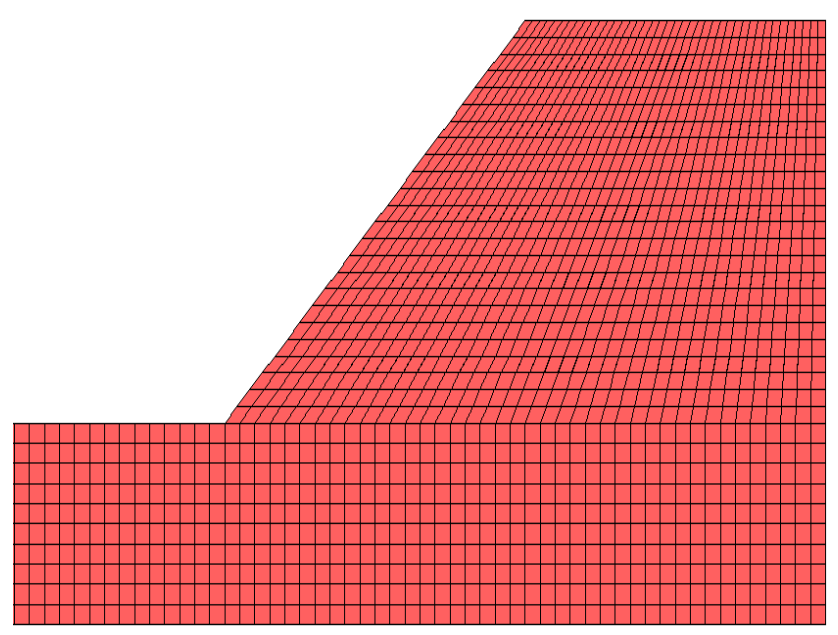

Fig. 8 Cross-section of open pit slope model geometry with domain descritization (finite difference mesh) 


\subsection{Model Set Up}

An entire cross-section through an open pit mines was modeled. A typical open pit slope model is shown in Figure 9 with 120 meters depth having $60^{\circ}$ slope angles of footwall and $70^{\circ}$ slope angle of hanging wall. $\mathrm{Bp}$ is the excavation boundary of the open pit mine. The majority of the models were mined in only one mining step.

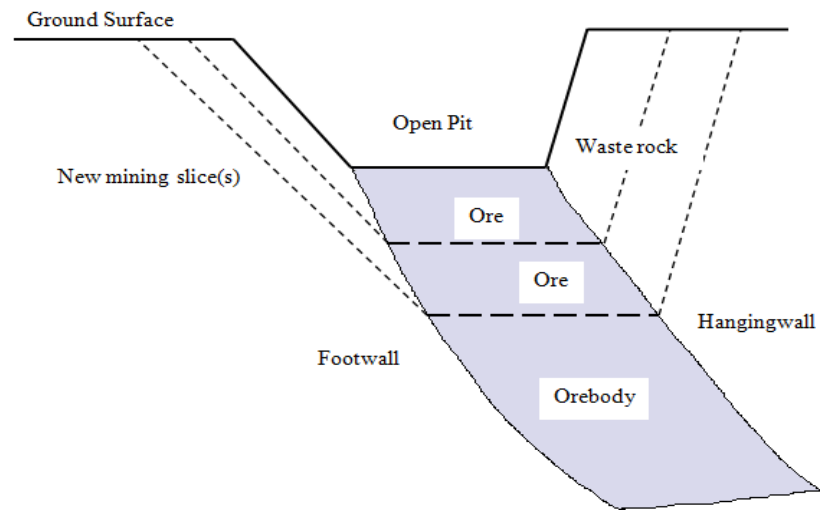

Fig. 9 Cross-section through a typical orebody mined as an open pit.

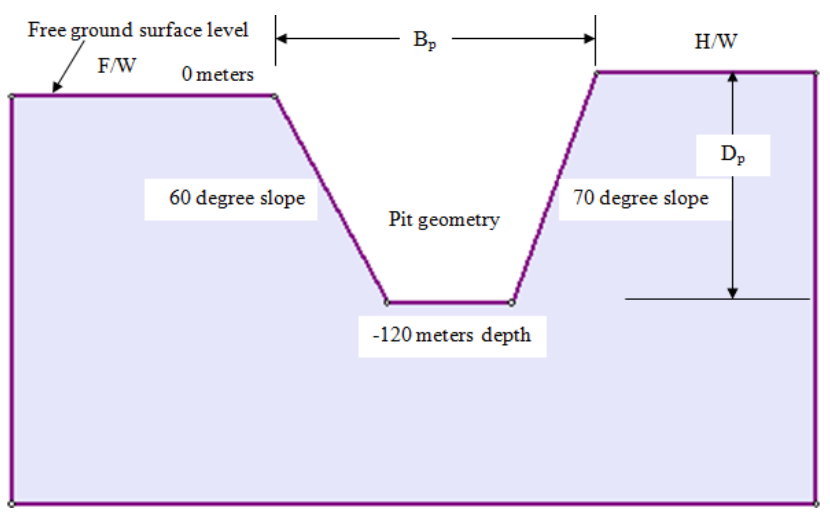

Fig.10 Model geometry for a 120 meter deep open pit mine.

Roller boundaries were applied on the left and right sides of the model, as well as on the bottom boundary was fixed to restrict movement perpendicular to each boundary. The ground surface was left as a free boundary (see Figure 11). The virgin stress state was initialized in the model, which was then allowed to come to initial (pre-mining) equilibrium. The vertical virgin stress was assumed to be solely due to the weight of the overlying rock mass. An out-of-plane horizontal stress was also specified, to avoid yield failure in the out-ofplane direction due to loss of confinement. The out-of-plane stress was set equal to the in-plane horizontal virgin stress. The influence zone due to the creation of surface excavation is generally taken as the 5-6 times of the boundary of the open pit geometry.

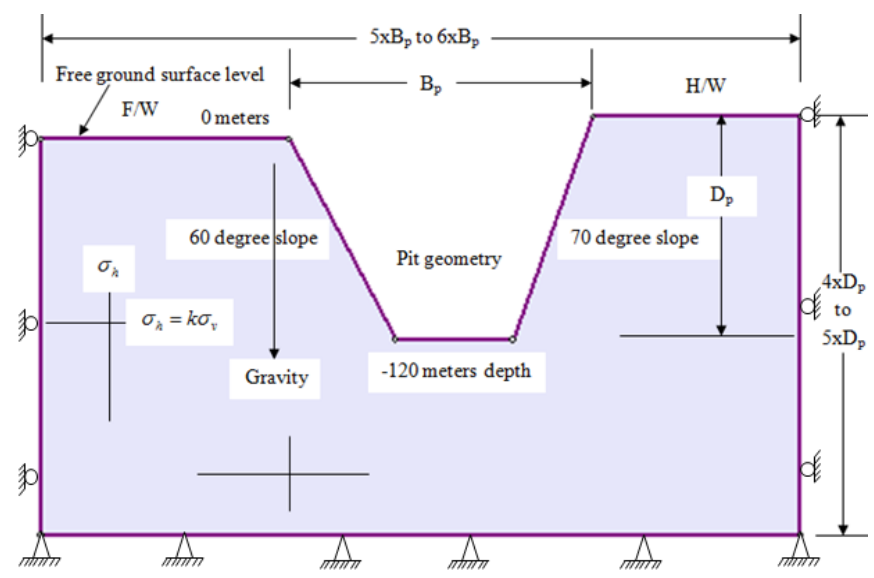

Fig.11 Required model sizes to minimize the influence from artificial boundaries.

\subsection{FDM Shear Strength Reduction Method}

In this paper the shear strength reduction method is implemented into the FLAC/Slope numerical code and its principal is that the reduction factor is divided simultaneously by values of intension parameter of slope, cohesion and friction angle, then obtaining a set of new values, and computing again with these new values as new input parameters. When the computing is not convergent, the corresponding values are called as the minimal safety factor of slope which approaches the extreme state. The SSR technique for slope stability analysis involves systematic use of finite difference analysis to determine a stress reduction factor (SRF) or factor of safety value that brings a slope to the verge of failure. The shear strengths of all the materials in a FDM model of a slope are reduced by the SRF. Conventional FDM analysis of this model is then performed until a critical SRF value that induces instability is attained. A slope is considered unstable in the SSR technique when its FDM model does not converge to a solution (within a specified tolerance).

Based on theory of elasticity and plasticity, FLAC/Slope finite difference method is applied to iterate for calculation of the stress and strain in term of certain load and boundary conditions of open pit slope. Here the slope is represented by an equivalent continuum in which the effect of discontinuities has been considered by reducing the properties and strength of intact rock to those of the rock mass. The slope has been analyzed for plane strain condition in small strain mode. At the base of the model boundary, both horizontal $(x)$ and vertical $(y)$ displacements are arrested by fixing the nodes. Along left and right of the boundary horizontal displacements are arrested. Initial stresses of magnitude $\sigma_{x x}=\sigma_{y y}=\sigma_{z z}=$ $10 \mathrm{MPa}$ are applied to all the zones. Stability analysis is carried out using Mohr - Coulomb failure criterion in FLAC/Slope model. FLAC/Slope calculates the factor of safety automatically using the shear strength reduction technique [38]. 


\subsection{Calculation of factor of safety (FoS) and strength reduction factor (SRF)}

The factor of safety, which is defined as the ratio of the total force available to resist sliding to the total force tending to induce sliding along any discontinuity surfaces [39]. Slope of open pit mines fails because of its material shear strength on the sliding surface is insufficient to resist the actual shear stresses. Factor of safety $(\mathrm{FoS})$ is a value that is used to examine the stability state of slopes. For FoS values greater than 1 means the slope is stable, while values lower that 1 means slope is unstable. In accordance to the shear failure, the factor of safety against slope failure is simply calculated as:

$$
F O S=\frac{\tau}{\tau_{f}}
$$

Where $\tau$ is the shear strength of the slope material of a typical open pit mine, which is calculated through MohrCoulomb criterion as given below.

$$
\tau=C+\sigma_{n} \tan \phi
$$

And, $\tau_{f}$ is the shear stress on the sliding surface along the two discontinuity plane and which can be calculated by the equation as given below:

$$
\tau_{f}=C_{f}+\sigma_{n} \tan \phi_{f}
$$

Where, $\mathrm{C}$ is cohesion and $\sigma_{\mathrm{n}}$ is normal stress. This method allows finding the safety factor of an open pit slope by initiating a systematic reduction sequence for the available shear strength parameters $c$ and $\phi$ to just cause the slope to fail. The reduction values of shear strength parameters $c_{\text {trial }}$ and $\phi_{\text {trial }}$ are defined as:

$$
C_{\text {trial }}=\frac{C}{S R F}
$$

$\phi_{\text {trial }}=\tan ^{-1}\left(\frac{\tan \phi}{S R F}\right)$

The values of ' $c_{\text {trial }}$ ' and ' $\phi_{\text {trial }}$ ' at which slope will have instability i.e. failure is calculated by FLAC/Slope using the strength reduction technique in which SRF is the strength reduction factor. The safety factor of the slope, FOS, is the value of SRF to bring the slope to failure.

An example of the FLAC/Slope model showing three different slope layers of a typical open pit mine has been considered for the analyses of mechanical behaviour of pit slope stability using the finite difference method. Thus factor of safety obtained $(\mathrm{FoS}=0.33)$ indicates the critically instable failure zones as shown in Figure 14, Figure 15 and Figure 17. FLAC/Slope, FDM Software has been illustrated, which presents domain discretization, critically instable failure zones and contours of maximum shear - strain rate in the slopes respectively as given below.

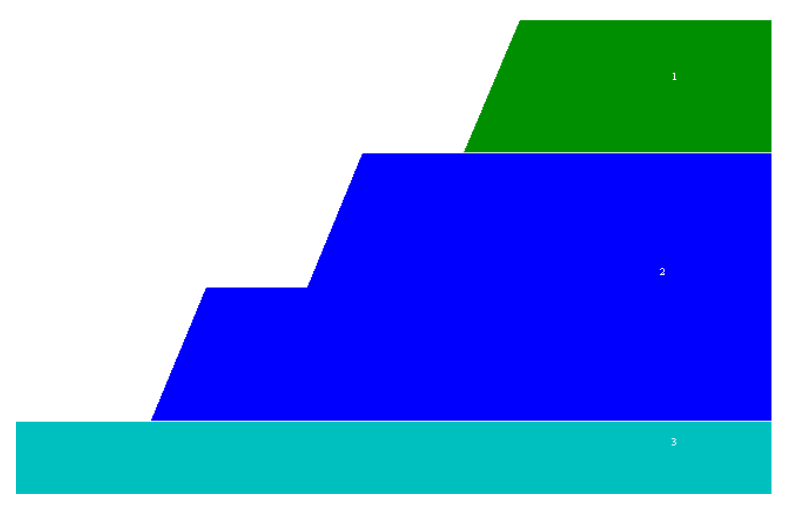

Fig. 12 FLAC/slope model showing the three different layers of an open pit slope.

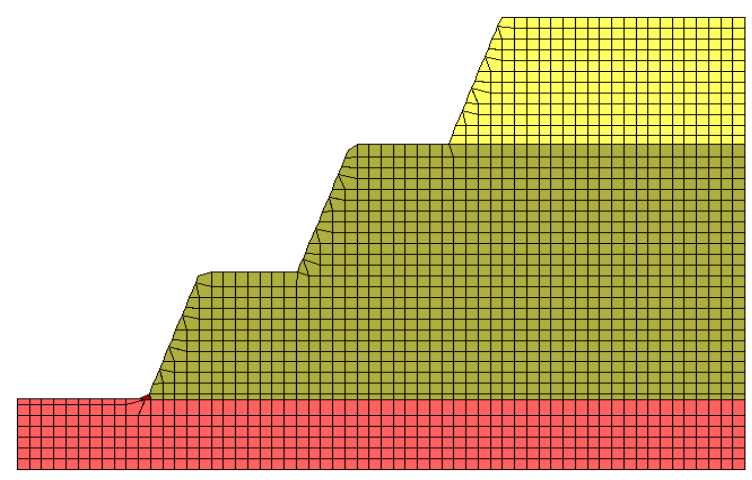

Fig. 13 FLAC/slope model with domain discretization.

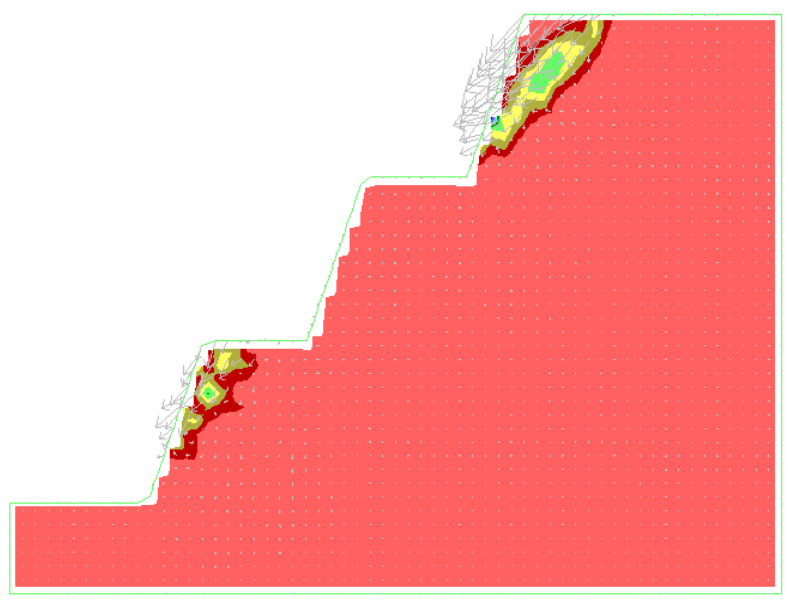

Fig. 14 FLAC/slope model showing critically instable failure zones. 


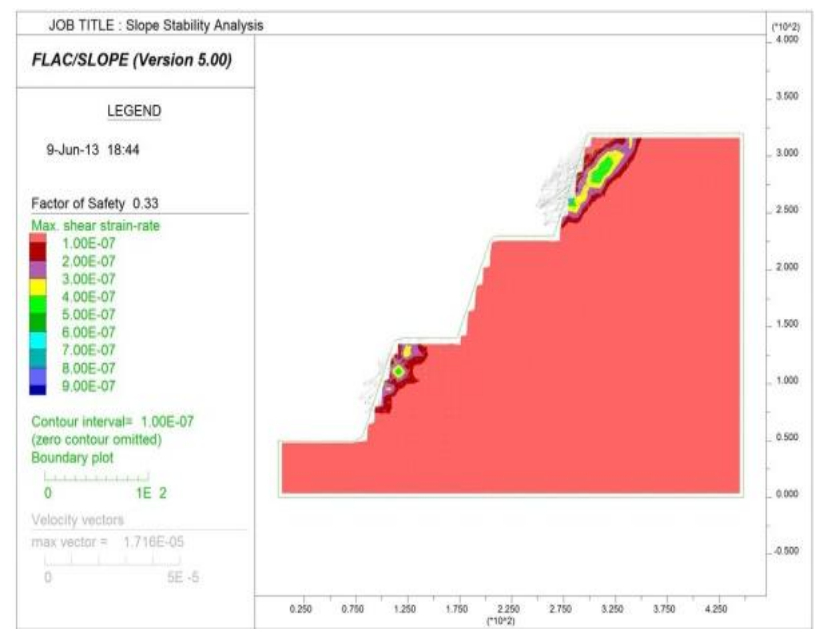

Fig. 15 FLAC/slope model showing critically instable failure zones as well as maximum shear-strain rate.

If multiple materials and/or joints are present, the reduction is made simultaneously for all materials. The trial factor of safety is increased gradually until the slope fails. At failure, the factor of safety equals the trial factor of safety (i.e. $f=$ FoS). [6] shows that the shear strength reduction factors of safety are generally within a few percent of limit analysis solutions when an associated flow rule, in which the friction angle and dilation angle are equal, is used.

The shear strength reduction technique has two main advantages over limit equilibrium slope stability analyses. First, the critical slide surface is found automatically, and it is not necessary to specify the shape of the slide surface (e.g. circular, log spiral, piecewise linear) in advance. In general, the failure surface geometry for slopes is more complex than simple circles or segmented surfaces. Second, numerical methods automatically satisfy translational and rotational equilibrium, whereas not all limit equilibrium methods do satisfy equilibrium. Consequently, the shear strength reduction technique usually will determine a safety factor equal to or slightly less than limit equilibrium methods.

Table - 1: Input parameters for the study of open pit slope stability analysis.

\begin{tabular}{|l|l|l|l|}
\hline Parameters & Values & Parameters & Values \\
\hline Slope height & $120 \mathrm{~m}$ & Slope angle & $45^{\circ}$ \\
\hline Water pressure & 0 & Density $\left(\mathrm{kg} / \mathrm{m}^{3}\right)$ & 2660 \\
\hline $\begin{array}{l}\text { Rock mass } \\
\text { friction angle }\end{array}$ & $43^{\circ}$ & Cohesion $(\mathrm{kPa})$ & 675 \\
\hline $\begin{array}{l}\text { Rock mass } \\
\text { tension modulus }\end{array}$ & 0 & $\begin{array}{l}\text { Bulk } \\
(\mathrm{GPa})\end{array}$ & 6.3 \\
\hline $\begin{array}{l}\text { Shear modulus } \\
(\mathrm{GPa})\end{array}$ & 3.6 & Joint friction angle & $40^{\circ}$ \\
\hline
\end{tabular}

\subsection{Numerical Analysis using FLAC/Slope}

Here, a Mohr-Coulomb FLAC/Slope model to simulate ubiquitous joint model has been discussed. The ubiquitous joint model in FLAC is a Mohr-Coulomb plastic solid with an embedded penetrative weak plane (ubiquitous joint) of specific orientation. In a ubiquitous joint model, plastic yielding may occur either in the Mohr-Coulomb solid or along the weak plane, or both, depending on the stress state, the orientation of the weak plane and the material properties of the solid and the weak plane. The yield criteria of the weak plane (ubiquitous joint) are:

$\tau_{s}=c_{j}+\sigma_{n} \tan \varphi_{j}$

Where, $\tau_{s}$ is shear strength, $c_{j}$ is ubiquitous joint cohesion, $\sigma_{n}$ is normal stress and $\varphi_{j}$ is ubiquitous joint friction angle

In the recent years, the 2-D finite difference code, FLAC has become very popular for design and analyses of slopes in continuum rock. This code allows a wide choice of constitutive models to characterize the rock mass and incorporates time dependent behaviour, coupled hydromechanical and dynamic modelling. An example of FLAC/Slope with single interface model that illustrates the circular type failure mechanism of weathered/jointed rock slopes has been given below in Figure 16 and Figure 17, which show the domain discretization and maximum shear strain rates occurred along the critically failure surfaces.

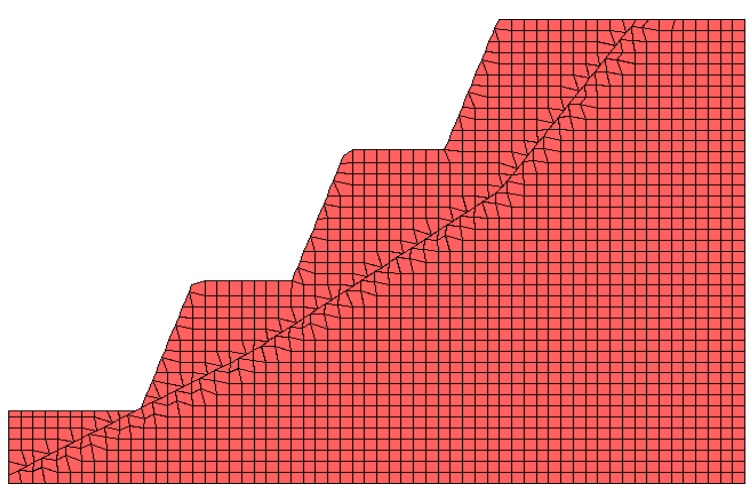

Fig. 16 FLAC/Slope single interface model with domain discretization. 


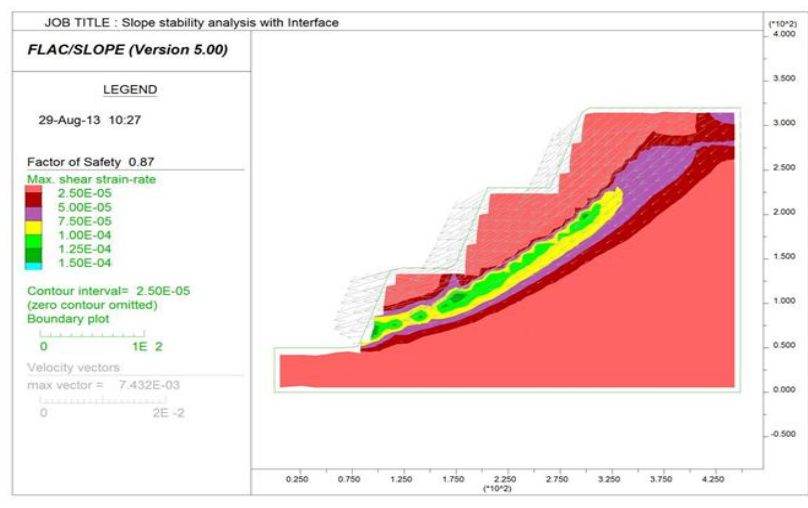

Fig. 17 FLAC/Slope model showing circular type failure.

\section{CONCLUSIONS AND SUMMARY}

Stability analyses of an open pit slope represents the critically failure mechanism of pit slopes in which finite element method, distinct element and finite difference methods provide a lot of benefits over limit equilibrium because these techniques are suitable for indication of the stress and strain distribution within critically instable failure zones, element displacement vectors and the plastic state of slopes. In this paper, the authors applied finite difference code, FLAC/Slope numerical analysis method for the slope stability analysis of a typical open pit mine and has found appropriate for the analysis of slope failure having similar geo-mining conditions. The numerical analysis technique of shear strength reduction method has been implemented into the finite difference method and found to be appropriate for the pit slope stability analysis. Intensity of mesh for simulation domain of all the applied techniques has been selected as a fine level for an acceptable accuracy and economical computation time. The various numerical models provided in this paper demonstrate that such modelling can be used to understand the behaviour of open pit slopes at the similar geo-mining conditions much better, on the other hand, captures the complicated variations of slope failure mechanisms. So that a geo-technical engineer can have a predictive capability for design of open pit slopes, and that predictive capability can only be achieved if the key features of the rock reality have indeed been captured in the slope models. This paper also examines the ability of the numerical technique (finite difference method) to capture the variation of factor of safety and failure mechanism of open pit slopes.

\section{ACKNOWLEDGEMENTS}

Authors express their acknowledgement to the Department of Mining Engineering, Indian School of Mines, Dhanbad for allowing the paper to be published, and also express their sincere gratitude to all those who help directly or indirectly in preparing the paper.

\section{REFERENCES}

[1] M. Souley, and F. Homand, (1996), "Stability of jointed rock masses evaluated by UDEC with an extended SaebAmadei constitutive law," Int. J of Rock Mech and Min Sci \& Geomech Abstracts, Vol. 33, pp. 233-244.

[2] ISRM (1981), "Suggested methods for the quantitative description of discontinuities in rock masses," Commission on the standardization of laboratory and field tests in Rock Mechanics,

[3] R.E. Hammah, T.E. Yacoub, B. Corkum, F. Wibowo and J.H. Curran (2007), "Analysis of blocky rock slopes with finite element shear strength reduction analysis," In Proceedings of the 1st Canada-U.S. Rock Mechanics Symposium, Vancouver, Canada, , pp. 329-334.

[4] R.E. Hammah, T.E. Yacoub, B. Corkum and J.H. Curran, (2008), "The Practical Modelling of Discontinuous Rock Masses with Finite Element Analysis," In Proceedings of the 42nd U.S. Rock Mechanics Symposium - 2nd U.S.-Canada Rock Mechanics Symposium, San Francisco, US.

[5] R.E. Hammah, T.E. Yacoub, B. Corkum and J.H. Curran, (2009), "A comparison of finite element slope stability analysis with conventional limit-equilibrium investigation," In Proceedings of the 58th Canadian Geotechnical and 6th Joint IAH-CNC and CGS Groundwater Specialty Conferences - GeoSask, Saskatoon, Canada.

[6] E.M. Dawson, W.H. Roth and A. Drescher, (1999) "Slope stability analysis by strength reduction," Geotechnique, vol. 49, no. 6, pp. 835-840.

[7] D.V. Griffiths and P.A. Lane, (1999), "Slope stability analysis by finite elements," Geotechnique, vol. 49, no. 3, pp. 387-403.

[8] T. Matsui and K.C. San, (1992) "Finite element slope stability analysis by shear strength reduction technique," Soils and Foundations, 32(1), pp. 59-70.

[9] W. Ming, F. Xundong and L. Huan, (2006), "Reducing method for intensity of slope stability analysis," civil engineering, 20(1), pp. 49-52. (in Chinese).

[10] S. Yuke, (1999), "Research on stability analysis for China open pits," Beijing, science and technology press.

[11] O. Hungr, (1987), “An extension of Bishop's simplified method of slope stability analysis to three dimensions," Geotechnique, 37(1), pp. 113-117.

[12] Casamichelle, P., Maugeri, M. \& Motta, E. (2004), "New approach for a three-dimensional analysis of slope stability," In Lacerda, Ehrlich, Fontoura \& Sayao (eds.) Landslides: Evaluation and Stabilization: pp. 1617-1623. Taylor \& Francis Group, London.

[13] Chen, Z., Wang, X. \& Haberfield, C. (2001), "A three dimensional slope stability analysis using the upper bound theorem," Part I: theory and analysis. Int. J. Rock Mech. Mining Sci. 38: pp. 369-78. 
[14] Dawson, E.M. \& Roth, W.H. (1999), "Slope stability analysis with FLAC". In Detournay \& Hart (eds.) FLAC and Numerical Modeling in Geomechanics, Proceedings of the International Symposium, Minneapolis, MN, USA, 1-3 September.pp. 3-9. Rotterdam: Balkema.

[15] Zettler, A.H., Poisel, R., Roth, W. \& Preh, A. (1999), "Slope stability based on the shear reduction technique in 3D. In Detournay \& Hart (eds.) FLAC and Numerical Modeling in Geomechanics, Proceedings of the International Symposium, Minneapolis, MN, USA, 1-3 September. pp. 11-16. Rotterdam: Balkema.

[16] Song W.K. \& Han K.C. (1999). Optimal design of highway slopes in a highly weathered rock. In Vouille \& Berest (eds.) ISRM International Congress. pp. 131133.

[17] Sjöberg J. (1999a), "Analysis of the Aznalcollar pit slope failures - a case study," In Detournay \& Hart (eds.), FLAC and Numerical Modeling in Geomechanics: pp. 63-70. Rotterdam: Balkema.

[18] Pant S.R. \& Adhikary D.P. (1999), "Implicit and explicit modeling of flexural buckling of foliated rock slopes," Rock Mech. Rock Engg. 32 (2): pp. 157-164.

[19] Steward D.P., Coulthard MA., Swindells C.F. (1996), “ Studies into the influence of underground workings on open pit slope stability," In Aubertin, Hassani \& Mitri (eds.) Rock Mechanics: 515-522. Rotterdam: Balkema.

[20] Cai F. \& Ugai K. (1999), "Effects of horizontal drains on ground water level and slope stability," In Yagi, Yamagami \& Jiang (eds.) Slope Stability Engineering: 551-556. Rotterdam: Balkema.

[21] Ng C.W.W., Zhang L.M., Ho K.K.S., Choy C.K. (2000), "Influence of laterally loaded sleeved piles on slope stability," GeoEng 2000. Melbourne. Australia.

[22] Cai F. \& Ugai K. (1999), "Effects of horizontal drains on ground water level and slope stability," In Yagi, Yamagami \& Jiang (eds.) Slope Stability Engineering: pp. 551-556. Rotterdam: Balkema.

[23] Fredlund D.G. \& Scoular R.E.G. (1999), "Using limit equilibrium concepts in finite element slope stability analysis,"In Yagi, Yamagami \& Jiang (eds.) Slope Stability Engineering: pp. 31-47. Rotterdam: Balkema.

[24] Jiang G.L. \& Magnan J.P. (1997), "Stability analysis of embankments: comparison of limit analysis with method of slices," Geotechnique. 47(4): 857-872.

[25] Griffiths D.V. \& Lane P.A. (1999), "Slope stability analysis by finite elements," Geotechnique. 49(3): pp. 387-403.

[26] Barton, N., Lien, R. and Lunde, J. (1974), "Engineering classification of rock masses for the design of tunnel support," Rock Mech., vol. 6, no. 4, 189-236.

[27] Bieniawski, Z.T. (1989), "Engineering Rock Mass classifications: a complete manual for engineers and geologists in mining, civil and petroleum engineering," Wiley, New York, 251.
[28] Hoek, E. and Karzulovic, A. (2000), "Rock mass properties for surface mines, in Slope Stability in Surface Mining," Hustrulid, McCarter and Van Zyl (eds.), SME, Colorado, 59-70.

[29] Serafim, J.L. and Pereira, J.P. (1983), "Considerations of the geomechanical classification of Bieniawski, Proc. Int. Symp. On Engineering Geology and Underground Construction," Lisbon. Portugal, Int. Ass. Engng Geol., vol. 1, II.33-II.42.

[30] Singh, V.K. and DhaR, B.B. (1994), "Stability analysis of open-pit copper mine by use of numerical modelling methods," Trans. Instn Min. Metall. (Section A: Min. Industry), vol. 103, A67-A74.

[31] Singh, V.K., Prasad, M., Singh, S.K., Ras, D.G. and Singh, U.K. (1995), "Slope design based on geotechnical study and numerical modelling of a deep open pit mine in India," Int. J. Surface Mining, Reclamation and Environment, vol. 9, 105-111.

[32] Sjöberg J. (1999b), "Analysis of failure mechanisms in high rock slopes. In Vouille \& Berest (eds.) ISRM International Congress. pp. 127-130.

[33] Duncan C.W and Christopher W.M. (2004), "Rock slope engineering.Civil and Mining, 4th Edition, Taylor \& Francis Group, pp. 5-7.

[34] Liu, B and Yan-hui, H, (2005), "The Principle, Example and Application Guide of The FLAC Program," Beijing: China Communications Press, pp 5-25.

[35] Itasca Consulting Group (2005), "Inc FLAC-2D (Fast Lagrangion Analysis of Continual in 2Demensions) Version5.0," User's Manual, USA.

[36] Zhu, J, Xu, B and Zhu, F et al. (2000), "FLAC The Finite Difference Programming and its Applying in Mining Engineering," China Mining, 8(4):pp. 78-82. (in Chinese).

[37] Wang, H and Yong, L, (2005), "Improved Method of Finite Element Analysis of Slope Stability," Chinese Journal of Rock Mechanics and Engineering, 24(13): pp. 2386-2391(in Chinese).

[38] Matsui, T. and San, K. C. (1992), "Finite Element Slope Stability Analysis by Shear Strength Reduction Technique," Soils and Foundations, vol. 32, no. 1, pp. 59-70.

[39] Hoek, E., and Bray, J. (1981) Rock slope engineering. 3rd Edition, The Institution of Mining and Mettalurgy, London, pp. 27. 